\title{
Project management information system effect decision making in the construction industry of Iraq
}

\author{
Elaf Dheyaa Abdulridha AL-Zubaidi \\ College of Engineering, University of ALQadisiyah, Iraq
}

\begin{abstract}
This study was intended to theorize fresh conceptual links between two common project management studies, the PMIS and paradigms of decision-making. This research examined the pragmatic conceptual connection between project management information system and low / high decision-making. The findings indicate that the function of Project Management Information Systems negotiation information overload and design overload for decision-making has been practiced and monitored. Overall, this provides a nice review of Western theories and ideas in the distinctive eastern framework.
\end{abstract}

\begin{tabular}{ll}
\hline Keywords: & $\begin{array}{l}\text { Resource capacity, Pay-off Time, Information processing, Transparency, Decision } \\
\text { Making }\end{array}$ \\
\hline
\end{tabular}

Corresponding Author:

Elaf Dheyaa Abdulridha AL-Zubaidi

College of Engineering

University of ALQadisiyah

Email: elaf.alzubaidi@qu.edu.iq

\section{Introduction}

Researchers have argued that implementing project management as a uniform strategy and even spending 100 percent of the moment does not provide certainty that the design will be effective. Project management is a distinctive system for offering the information required to make strategic company choices. Project management usually recognizes that it serves a crucial part in the successful implementation of business strategies. As businesses contend, project management carries out their policies. For the past 30 years, project management has been recognized as an efficient tool for managing new or complex activities. Managers need to create fast choices, allocate limited funds effectively, and concentrate obviously. Management poses countless difficulties in organisations that concurrently engage in many initiatives.

Although it is presumed that the traditional project management methods accessible to the Project Manager are self-evidently right, the initiatives still work. With this significant conjecture leadership endeavor in mind, organizing and implementing a venture was very crucial. The organization will overhaul the Project Management Information System (PMIS) to boost plan execution. In the framework of project executives and support group, PMIS are organizations that provide an attitude, facilities, types, commodities, governance and technology. PMIS has discovered empirical evidence that is immediately and indirectly related to timeconsuming decision-making and contributes to venture achievement [1]. [2] Information systems clearly researched, studying in specific the impacts of the information system characteristics on their presumed usefulness. They discovered that high-quality information is essential in an information system because it enables consumers to create sensible choices and thus enhances the project manager's job efficiency. On the other side, information systems that provide consumers with hazardous and untrue information have a adverse effect on their usefulness. These instruments are typically provided in PMIS software applications such as Primavera and Microsoft Project, which are supposed to assist and enhance decision making, such as threat effect estimates, threat classification and ranking. We predict the PMIS's information quality to be positively related to an appropriate choice based on current literature.

Construction activities are frequently acknowledged as effective when finished on timetable, within schedules and in accordance with requirements and stakeholder fulfillment. Because of their technical and complicated nature, even with good designs and plans, it is of the utmost importance that they are well managed for 
success. For instance, companies provide bad service through bad paperwork, bad decision-making and extended moment changes while executing initiatives contributing to design disturbance or complete inability. How do company executives assist them create the correct choice? How are individuals processing a ton of information? How do they evaluate and choose options? How do you assess and perceive prospective incidents or dangers? There are multiple elements or reasoning procedures that could call for fragile decisions. These contain:

- Don't have clearly results

- No enough time to decide

- Ignorance of evaluation techniques

- Inaccurate forecasting of the effects of specific actions

- Inaccurate forecasting of external influences

- Uncritical acceptance of others' judgments

- Uncritical acceptance of subjective needs and feelings

Implementation of the worksite leadership initiative, aimed at enhancing project execution objectives through project management rules, reviewing project execution and establishing the fundamental framework, learning, learning and advising plan leadership, guarantees that the supreme goal of improving the project is to decrease the effect of incorrect choices by different organisations. With bad project management results, significant leadership difficulties have become the use of project management for some corporate group, one significant manufacturing. Different methods and equipment for overall use in project management. This article examined how the use of PMIS can assist handle initiatives, and in specific team construction activities, with a perspective to enhancing information quality, effectiveness and effectiveness throughout the entire design stage.

\subsection{Project management information system (PMIS)}

PMIS discovered empirical evidence immediately and indirectly related to timely decision-making, contributing to design achievement [1]. [2] In specific, the impacts of the information system features on their presumed usefulness have been fully examined by the information systems. They found that high-quality information is essential in an information system as it promotes customer decision-making and thus increases the project manager's job efficiency. On the other hand, the usefulness of information schemes that provide people with unreliable and incorrect information is adversely impacted. These instruments are usually included in PMIS software applications such as Primavera and Microsoft Project to assist and enhance decision-making, such as risk impact assessment and risk classification and rating. Based on current literature, we expect that the performance of PMIS information will be related to a successful choice.

\subsection{Project overload}

There is a restriction on the amount of design executives that can address the property of the available restriction at the same moment. System and board can be helpful as expert design understanding of what to do and how to operate in institutionalized procedures. Since the use of labor and pay-off cannot be adjusted with too little or excessive tables can change without much weight throughout the project [3]. Surplus schemes and scrutiny of objective weight changes from the mere job of project leadership to practice, whereas too few sheets mistake what to do next. The interdependencies and communication at the core of the venture are other problems and track lead times. Because of their design plans (comparatively) based on each other in distinct design settings, awareness of available moment and resources is crucial to the advancement of the company at every minute in moment. Limited moment must be achieved for initiatives that can provide more than most opportunities for restoration and distance estimation. Project employees understand it's essential to evaluate initiatives. However, in practice, because the weight of each project time is given before the following tasks, they can evaluate and learn from what has been wrong and right in the past. This indicates that design directors may have too little time at the start of the venture to conform with high-information PMIS and the core itself in view of the responsibility of excess initiatives [4]. 


\subsection{Information overload}

The connection between overloading information and decreasing design efficiency is created [5]. More information can minimize the efficiency of decision-making over and above some optimum level. Given the difficulties of defining relevant information from the complete information accessible and distractions, too much information can trigger issues in choosing suitable information, which decreases the moment invested handling information [5]. Most of the time, the number of projects completed repeated the information available to the project manager in various projects. If the design information is so big for each venture, the service atmosphere can be hazardous. The absence of ease and information about the venture is demonstrated by the multi-project setting. Not extended to desperately involve an urgent, leading to questionable employment initiatives as to information and to whom it should be conveyed and in what ability. It has been difficult to find performance information in the environments of any project manager [3].

\subsection{Decision making procedure}

Due to the recursive character of decision-making, there is probable to be a forward and reverse motion in pursuing the operation. The following are the most popular measures in decision-making:

1.4.1 Create a constructive environment: A goal must be created in establishing a building atmosphere. The people involved play an important role in the decision and a good stakeholder analysis is to be done to ensure that the right people are asked the right question. Not affecting the individuals involved in a choice is considered to be an exercise of violence.

1.4.2 Generating potential solutions: This stage is critical to decision-making. The stronger your options, the more probably you are to create a healthy choice. Generating options enables an in-depth glance at the issue and the more you suppose that a stronger answer can be found, the more probable it is to create the greatest choice feasible. All options as well as no choice should be regarded. In as much as in most instances no choice could be catastrophic, it is necessary to be a stronger choice than the options accessible. Brain storming is the most common instrument used to produce solutions.

1.4.3 Evaluating alternatives: In decision-making, there is always a degree of confusion about any option. Analysis of the feasibility, danger and implications of each option is crucial. There are numerous instruments used to evaluate these options, including linear programming, cost-benefit assessment, choice tree, modeling and PMI method.

1.4.4 Choose the best alternative: After evaluating the options, the finest alternative that suits the goal is selected. This may require choosing as a community. The use of approach in decision-making relies on the complexity of the decision-maker. A pre-programmed automated system could be used to select the finest option.

1.4.5 Check your decision: This is another significant phase, but it is ignored most of the moment. You need to verify your choice and make sure that all circumstances have been regarded and that the finest choice has been taken. The disastrous effects that over-confidence, group thinking and other mistakes in decision-making have made on the world economy are evident.

1.4.6 Communicate your decision and move to action: The choice to take out the venture and the individuals impacted by it should be well conveyed to the individuals. In the communication phase, prevent being economical with the reality, guarantee that the predicted advantage, danger and probable drawbacks are well described.

\subsection{Game theory with decision making}

Game Theory (GT) is a science sector concerned with the research and evaluation of people ' spatial, reasonable choice procedures and their relationships in a (cultural) setting. It focuses on the research of "respects in which social relationships between economic agents generate results with regard to officials ' 
choices (or value)" [6] regardless of whether the results of their efforts were intended. [7] argued' we are mostly speaking about a research of mathematical or statistical designs of disputes and partnerships between smart and rationally choosing topics. Game theory offers two particular methods of assessment. One of them is mathematical techniques for analyzing circumstances and the other is statistical analysis to create choices that affect the position of one or the other. The topic of his research is the comprehension, interpretation or forecast of the choices of a prospective individual with the environment.

\subsection{Conceptual framework of decision making}

In the early phase of execution of the company's plan, the accomplishment of the information system depends on many factors. Implementing a comprehensive and cross-functional information system is usually volatile and unsafe for organizational staff and customers. The execution team is critical to a smooth and effective implementation for clients to adopt a new information system that could alter their working technique to some extent.

Many other organizational theories suggested that employees need to develop beyond their formal requirements for actual outcomes for the organization [8]. The authors themselves considered cooperative behavior of employees, such as cooperation, as providing views and encouraging the organization's favourable atmosphere, which are glues that link the organization. Technical knowledge, process skills, communication and strategic planning are developed from the community member's point of perspective as important determinants for the project's success. In reality, clients have a favourable assessment of the information systems by the growth community, which will ultimately increase the adoption of innovations [9].

PMIS led in enterprises engaging in projects when considering their effectiveness or sustainability. In sectors such as design, IT, building and pharmaceutical industries, these projects are most common. They plan, employ, organize, monitor, monitor and evaluate the main tasks of the projects [10]. To have the impact of PMIS, people should be satisfied, and the use of filled customers should be achieved effectively. Also, the hierarchy of development plan expenditure, timing and determination should be affected in the interim, effective PMIS. While company managers in distinct types of business are gradually concentrating on PMIS, they will depend very slightly on the features of this framework that adds to the success of the venture. The effect of the PMIS on work outcomes is more prominent for the project manager in conjunction with the effect of the most significant in the PMIS.

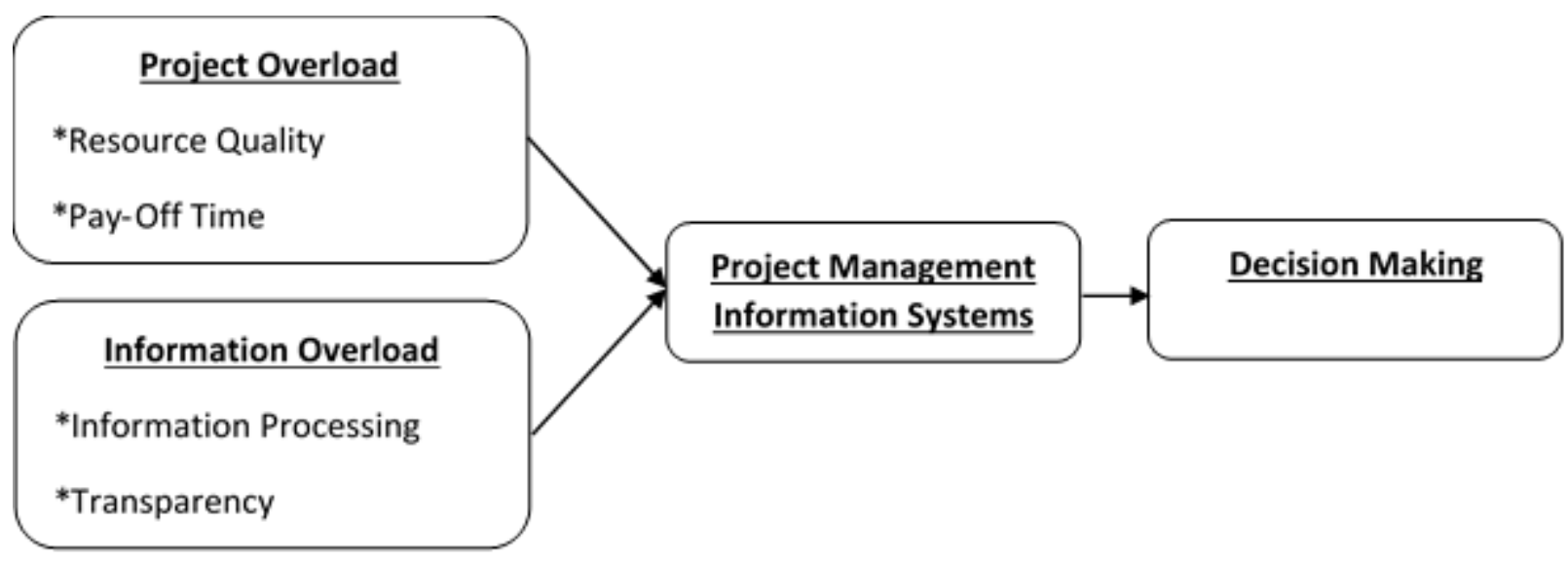

Figure 1. Conceptual framework

\section{Methodology}

The questionnaire is split into two components. The first portion will comprise of participants with population questions including sex, age, academic history, etc. The second component is split into four factors (Project overload and information overload and Project Management Information System (PMIS) and decisionmaking).

Resource capacity was measured with 8-item scale developed by [11]. Pay-off Time was measured with 5item scale developed by [11]. Information processing was measured with 9-item scale developed by [5]. 
Transparency was measured with 6-item scale developed by [5]. PMIS was measured with 6-item scale developed by [1]. Decision making was measured with 7-item scale developed by [1].

This research sought to explore the impact of choosing on the achievement or inability of initiatives in Iraq's building businesses. All the feedback collected was evaluated using SPSS (Statistical Package for Social Sciences) bootstrapping. This specimen is predicted at 148 based on the methods used [12]. The most respondent is masculine $(\mathrm{N}=136 ; 92$ percent $)$ and the remainder of the respondent is woman $(\mathrm{N}=12 ; 8$ percent).

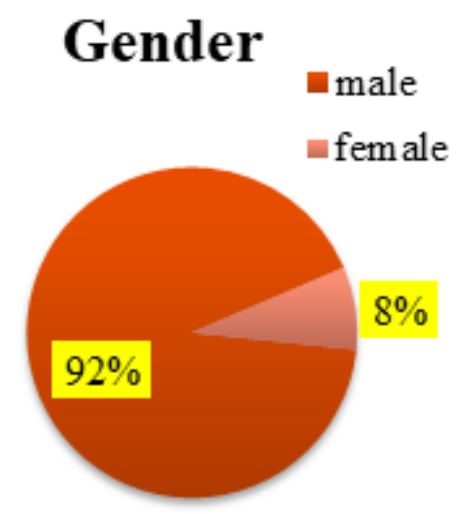

Figure 2. Respondent profile

It can be seen that age bracket 36 to 45 years has the largest percentage with (37 percent) and the lowest commonly for death between 56 and above is 11 percent. The participants held a B.Sc. Degree of 75 percent, accompanied by a Master degree of 20 percent, stating that most participants have the correct context to reply study requests. Finally, 5 percent of the participants held a PhD where 72 percent of the staff have 5 to 10 years of expertise.

\section{Results and discussion}

The appropriate statistical techniques were used to assess the importance between dependent varying and autonomous variable to explore the inclusion between study hypotheses, questionnaire elements and information interpretation. Table 1 demonstrates the connection between hypotheses of studies, conditional and autonomous factors and statistical techniques.

Table 1. The relation between research hypotheses and proposed method

\begin{tabular}{|l|l|l|l|l|}
\hline $\begin{array}{l}\text { Research } \\
\text { Hypothesis }\end{array}$ & $\begin{array}{l}\text { Independent } \\
\text { Variables }\end{array}$ & Mediation & $\begin{array}{l}\text { Dependent } \\
\text { Variables }\end{array}$ & $\begin{array}{l}\text { Statistical } \\
\text { Methods }\end{array}$ \\
\hline H1 & $\begin{array}{l}\text { Resource } \\
\text { capacity }\end{array}$ & & PMIS & Liner Regression \\
\hline H2 & Pay-off Time & & PMIS & Liner Regression \\
\hline H3 & $\begin{array}{l}\text { Information } \\
\text { processing }\end{array}$ & & PMIS & Liner Regression \\
\hline H4 & Transparency & & PMIS & Liner Regression \\
\hline H5 & PMIS & & $\begin{array}{l}\text { Decision } \\
\text { making }\end{array}$ & Liner Regression \\
\hline H6 & $\begin{array}{l}\text { Resource } \\
\text { capacity }\end{array}$ & & $\begin{array}{l}\text { Decision } \\
\text { making }\end{array}$ & Liner Regression \\
\hline H7 & Pay-off Time & & $\begin{array}{l}\text { Decision } \\
\text { making }\end{array}$ & Liner Regression \\
\hline H8 & $\begin{array}{l}\text { Information } \\
\text { processing }\end{array}$ & & $\begin{array}{l}\text { Decision } \\
\text { making }\end{array}$ & Liner Regression \\
\hline H9 & Transparency & & $\begin{array}{l}\text { Decision } \\
\text { making }\end{array}$ & Liner Regression \\
\hline
\end{tabular}




\begin{tabular}{|l|l|l|l|l|}
\hline $\begin{array}{l}\text { Research } \\
\text { Hypothesis }\end{array}$ & $\begin{array}{l}\text { Independent } \\
\text { Variables }\end{array}$ & Mediation & $\begin{array}{l}\text { Dependent } \\
\text { Variables }\end{array}$ & $\begin{array}{l}\text { Statistical } \\
\text { Methods }\end{array}$ \\
\hline H10 & $\begin{array}{l}\text { Resource } \\
\text { capacity }\end{array}$ & PMIS & $\begin{array}{l}\text { Decision } \\
\text { making }\end{array}$ & Bootstrapping \\
\hline H11 & Pay-off Time & PMIS & $\begin{array}{l}\text { Decision } \\
\text { making }\end{array}$ & Bootstrapping \\
\hline H12 & $\begin{array}{l}\text { Information } \\
\text { processing }\end{array}$ & PMIS & $\begin{array}{l}\text { Decision } \\
\text { making }\end{array}$ & Bootstrapping \\
\hline H13 & Transparency & PMIS & $\begin{array}{l}\text { Decision } \\
\text { making }\end{array}$ & Bootstrapping \\
\hline
\end{tabular}

\subsection{Correlations, mean and standard deviation}

The correlation results from Table 1 showed that Resource capacity has ( $\mathrm{r}$ value $=-.303$, significant value $\mathrm{p}<$ 0.01 ), Pay-off Time has ( $\mathrm{r}$ value $=-.282$, significant value $\mathrm{p}<0.01$ ), Information processing ( $\mathrm{r}$ value $=-.276$, significant value $p<0.01)$, Transparency $(\mathrm{r}$ value $=-.365$, significant value $\mathrm{p}<0.01$ ), were negatively and significantly associated and PMIS with decision making and ( $\mathrm{r}$ value $=0.705$, significant value $\mathrm{p}<0.01$ ) was positively and significantly associated with decision making. The table 2 below also shows the mean and standard deviation of independent, dependent and mediation variables.

Cronbach's alpha reliability scores should be greater than 0.7 (minimum) [13-15]. An alpha of more than 0.7 would indicate that the items are homogeneous and measuring the same constant.

Table 2. Correlations, mean, standard deviation and Cronbach's alpha

\begin{tabular}{|l|l|l|l|l|l|l|l|l|}
\hline & Mean & $\begin{array}{l}\text { Std. } \\
\text { Deviation }\end{array}$ & RC & POT & IO & T & PMIS & DM \\
\hline RC & 4.1716 & .40272 & $\mathbf{( . 7 4 8 )}$ & & & & & \\
\hline POT & 4.1427 & .32701 & $.374 * *$ & $\mathbf{( . 7 6 0 )}$ & & & & \\
\hline IO & 4.1971 & .41742 & $.421^{* *}$ & $.377^{* *}$ & $\mathbf{( . 8 3 5})$ & & & \\
\hline T & 4.3544 & .38975 & $.529 * *$ & $.508^{* *}$ & $.507^{* *}$ & $\mathbf{( . 7 5 9 )}$ & & \\
\hline PMIS & 1.9809 & .41446 & $-.253^{* *}$ & $-.240^{* *}$ & $-.213^{* *}$ & $-.330^{* *}$ & $\mathbf{( . 7 1 2})$ & \\
\hline DM & 1.9228 & .42463 & $\mathbf{- . 3 0 3} * *$ & $\mathbf{- . 2 8 2} * *$ & $-.276^{* *}$ & $\mathbf{- . 3 6 5 * *}$ & $\mathbf{. 7 0 5 * *}$ & $\mathbf{( . 8 8 3 )}$ \\
\hline
\end{tabular}

Note: $\mathrm{N}=148, \mathrm{RC}=$ Resource capacity, POT $=$ Pay-off Time, $\mathrm{IO}=$ Information processing, $\mathrm{T}=$ Transparency, DM = Decision Making, Reliabilities are given in Bold in parenthesis

\subsection{Regression analysis}

Regression assessment is between PMIS's property capacity, pay-off time, information processing, and responsibility. Responding from the respondents ' evaluation, strongly focused on the remaining association. As a consequence, these results suggested that the identification of suitable information is easy and safe for a development manager due to the implementation of PMIS [5] and absence of information security to reduce the appropriate method. Overall, PMIS decreases information overload [3].

Table 3. Results of regression analysis impact on PMIS

\begin{tabular}{|l|l|l|l|l|}
\hline Variables & $(\boldsymbol{\beta})$ & $\mathbf{R}$ Square & $\Delta$ R Square & Sig \\
\hline Resource capacity & -.224 & .050 & .050 & .006 \\
\hline Pay-off Time & -.192 & .037 & .037 & .019 \\
\hline Information processing & -.330 & .109 & .109 & .000 \\
\hline Transparency & -.179 & .032 & .032 & .029 \\
\hline
\end{tabular}

Regression analysis is for PMIS decision-making, asset ability, pay-off period, information handling, and accountability. Responded from the assessment of the participants, heavily decided on the connection that remains. Overall, this research indicates that project executives can make the correct choice owing to PMIS while simultaneously managing distinct tasks and reducing job overload variables $[3,4]$. These results showed 
that it is easy for project managers to take the right decision [5] and reduce the overall effect of information overload $[3,5]$ due to the identification and timely identification of relevant information through PMIS.

Table 4. Results of regression analysis impact on decision making

\begin{tabular}{|l|l|l|l|l|}
\hline Variables & $(\boldsymbol{\beta})$ & $\mathbf{R}$ Square & $\Delta$ R Square & Sig \\
\hline PMIS & .705 & .497 & .497 & .000 \\
\hline Resource capacity & -.233 & .054 & .054 & .004 \\
\hline Pay-off Time & -.235 & .055 & .055 & .004 \\
\hline Information processing & -.365 & .133 & .133 & .000 \\
\hline Transparency & -.187 & .028 & .028 & .023 \\
\hline
\end{tabular}

\subsection{Bootstrapping}

PMIS mediates between resource capacity and decision-making. The bootstrapping test is PMIS that mediates the relationship between capacity of the resource and decision making. Responded from the respondents ' analysis, strongly agreed on the mediating relationship that exists. The regression of decision-making with resource capacity was significant in Step 1 of the mediation model, coefficient value $=-0.1558$, significant value $=.0496$. Step 2 showed that the regression of the PMIS was also significant with Resource capacity, coefficient value $=-0.3043$, significant value $=.0033$. Step 3 of the mediation process showed that the mediator (PMIS), controlling with the decision making, was significant, coefficient value $=.6926$, significant value $=0.0000$ which means $100 \%$ significantly.

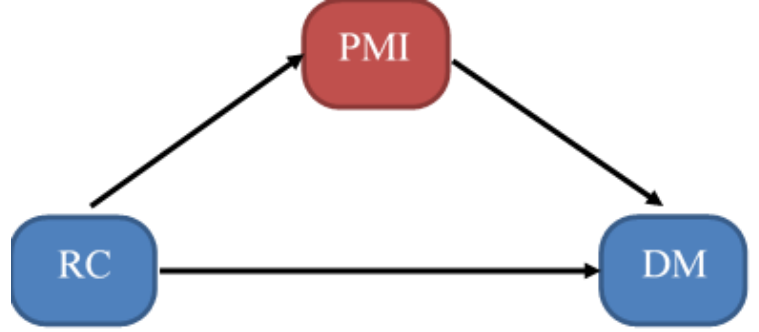

Figure 3. PMIS mediates between resource capacity and decision-making

PMIS mediates between pay-off time and the decision-making. PMIS is the bootstrapping test that mediates the relationship between pay-off time and decision-making. Responded from the respondents ' analysis, strongly agreed on the mediating relationship that exists. The regression of decision-making with pay-off time was significant in Step 1 of the mediation model, coefficient value $=-0.1400$, significant value $=0.0282$. Step 2 showed that the regression of the PMIS was also significant with Pay-off Time, coefficient value $=-0.2606$, significant value $=.00019$. Step 3 of the mediation process showed that the mediator (PMIS), controlling with the decision making, was significant, coefficient value $=.6876$, significant value $=.0000$ which means $100 \%$ significantly.

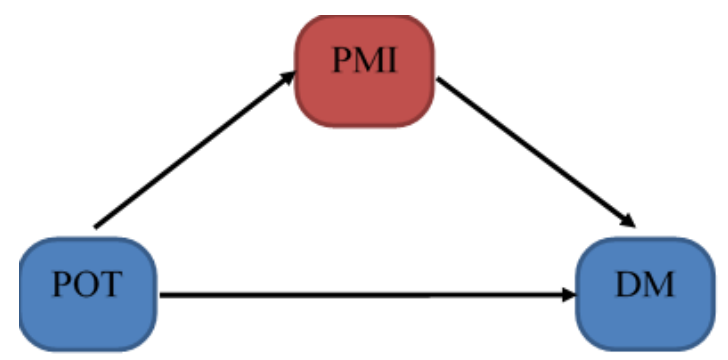

Figure 4. PMIS mediates between pay-off time and the decision-making

PMIS mediates between the Information processing and decision-making. The bootstrapping test is PMIS that mediates the relationship between processing information and making decisions. Responded from the respondents ' analysis, strongly agreed on the mediating relationship that exists. Step 1 of the mediation model, there was significant regression of decision-making with information processing, coefficient value $=$ 0.1617 , significant value $=.0165$, Step 2 showed that the regression of the PMIS was also significant with 
Information processing, coefficient value $=-.0 .3506$, significant value $=0.0000$ and Step 3 of the mediation process showed that the mediator (PMIS), controlling with the decision making, was significant, coefficient value $=.6720$, significant value $=.0000$ which also means $100 \%$ significantly .

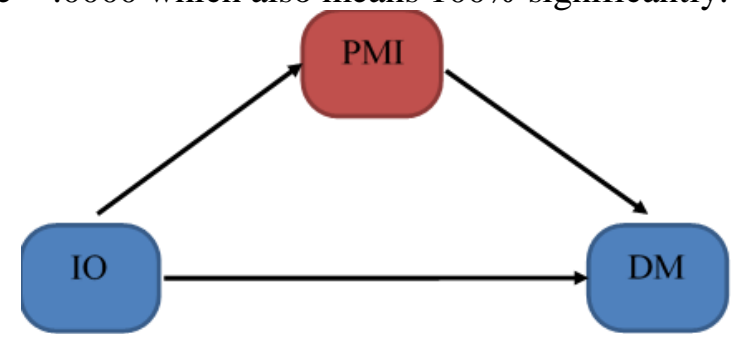

Figure 5. PMIS mediates between information processing and decision-making

PMIS mediates between transparency and decision-making. PMIS is the bootstrapping test that mediates the relationship between transparency and decision-making. Responded from the respondents ' analysis, strongly agreed on the mediating relationship that exists. The regression of transparency decision-making was significant in Step 1 of the mediation model, coefficient value $=-0.1346$, significant value $=0.0094$. Step 2 showed that the regression of the PMIS was also significant with Transparency, coefficient value $=-0.2114$, significant value $=0.0094$. Step 3 of the mediation process showed that the mediator (PMIS), controlling with the decision making, was significant, coefficient value $=0.6932$, significant value $=.0000$ which refers also to $100 \%$ significantly.

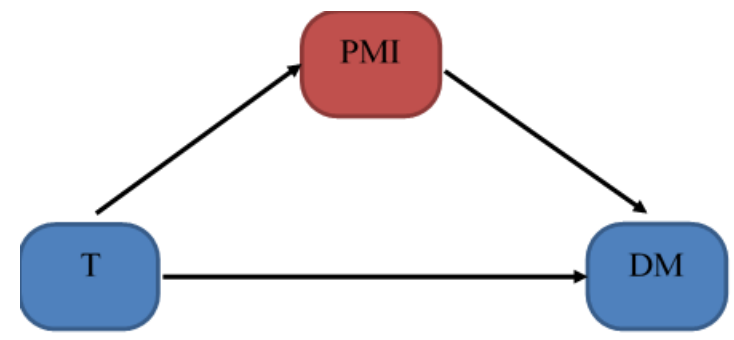

Figure 6: PMIS mediates between transparency and decision-making

\section{Conclusion}

This research showed how the exits between initiatives and project management differ and how the prevalent use of such words can contribute to misunderstanding. It also attempted to emphasize how distinct project leadership goals are and how project leadership relies on achieving particular and short-term goals relative to a project's wider goals. The result is that making the project management group fully accountable for achievement would seem inadequate and that the client would be more interested in project development and use. There is also a need to improve the difference between team achievement and project inability and plan leadership concerns. Three assessment requirements could be used to assess project achievement, not only on the grounds of project leadership techniques, but also on the grounds of other internal requirements that are essential for effective plan implementation, beginning with layout, through growth and use, and finishing with completion.

Therefore, in order for a plan to perform, the function of project management in schools must be stronger valued and this function must be put in the framework of a bigger team alongside other internal requirements and long-term requirements. The project manager should also allow the client to fully engage in the scheduling and manufacturing stages while at the same moment expanding the design team's involvement to the usage stage. This would be correctly implemented in a project evaluation method that examines not only execution procedures, but also economic and financial results. The performance and real use of PMIS information appears to have an effect on decision-making. Therefore, future study should bring into consideration a wider variety of variables and create a stronger knowledge of, in specific, the information supplied in PMIS and the use of PMIS information systems. Also important for further studies are counterintuitive results on the effect of initiatives and information overload on the performance of PMIS information. Future studies should concentrate on how much performance of PMIS information is improved by design overload and information overload. Another exciting element of further information studies could 
be the prospective beneficial impact of the important quantity of graphical records produced by PMIS to decrease the inverse impact of overloading information.

\section{Further works and limitations}

The performance of decision-making seems to be influenced by the value of PMIS information and the real use of this information. Future study should therefore bring into consideration a wider number of variables and create a stronger understanding of PMIS information and use of PMIS information constructs, in particular.

Another important finding for further studies is the counterintuitive finding concerning the impact of operation and information overload on the performance of PMIS information. Future studies should concentrate on the effect to which design overload and information overload enhances the performance of PMIS information. An extra exciting element for further studies on information overload could be the feasible beneficial impact of the significant quantity of graphical records produced by PMIS to decrease the inverse impacts of information overload.

\section{References}

[1] L. Raymond and F. Bergeron, "Project management information systems: An empirical study of their impact on project managers and project success," International Journal of Project Management, vol. 26, pp. 213-220, 2008.

[2] K. A. Saeed and S. Abdinnour-Helm, "Examining the effects of information system characteristics and perceived usefulness on post adoption usage of information systems," Information \& Management, vol. 45, pp. 376-386, 2008.

[3] M. C. Caniëls and R. J. Bakens, "The effects of Project Management Information Systems on decision making in a multi project environment," International Journal of Project Management, vol. 30, pp. 162-175, 2012.

[4] M. Levin, Ethnicity and Aboriginality: case studies in ethnonationalism: University of Toronto Press, 2015.

[5] C. A. O'Reilly, "Individuals and information overload in organizations: is more necessarily better?," Academy of management journal, vol. 23, pp. 684-696, 1980.

[6] R. Kimball and M. Ross, The data warehouse toolkit: the complete guide to dimensional modeling: John Wiley \& Sons, 2011.

[7] V. L. Souter, R. P. Kapur, D. R. Nyholt, K. Skogerboe, D. Myerson, C. C. Ton, et al., "A report of dizygous monochorionic twins," New England Journal of Medicine, vol. 349, pp. 154-158, 2003.

[8] P. M. Podsakoff, S. B. MacKenzie, J. B. Paine, and D. G. Bachrach, "Organizational citizenship behaviors: A critical review of the theoretical and empirical literature and suggestions for future research," Journal of management, vol. 26, pp. 513-563, 2000.

[9] C. M. Ridings, D. Gefen, and B. Arinze, "Some antecedents and effects of trust in virtual communities," The Journal of Strategic Information Systems, vol. 11, pp. 271-295, 2002.

[10] M. J. Liberatore and B. Pollack-Johnson, "Factors influencing the usage and selection of project management software," Engineering Management, IEEE Transactions on, vol. 50, pp. 164-174, 2003.

[11] T. Hochdorfer and G. Bjarnason, "Project Overload in Project Based Organizations-Causes, Symptoms and Effects: A study of Project Members and their Projects," 2007.

[12] R. V. Krejcie and D. W. Morgan, "Determining sample size for research activities," Educ Psychol Meas, 1970.

[13] J. M. Cortina, "What is coefficient alpha? An examination of theory and applications," Journal of applied psychology, vol. 78, p. 98, 1993.

[14] H. R. Bdulshaheed, Z. T. Yaseen, and I. I. Al-barazanchi, "New approach for Big Data Analysis using Clustering Algorithms in Information," Jour Adv Res. Dyn. Control Syst., vol. 2, no. 4, pp. 1194 1197, 2019.

[15] S. Rashid, A. Ahmed, I. Al Barazanchi, A. Mhana, and H. Rasheed, "Lung cancer classification using data mining and supervised learning algorithms on multi-dimensional data set," Period. Eng. Nat. Sci., vol. 7, no. 2, pp. 438-447, 2019. 